\title{
KOMPARASI TEBAL PERKERASAN LENTUR METODE AASHTO 1993 DENGAN METODE BINA MARGA
}

\author{
Wesli $^{1)}$, Said Jalalul Akbar ${ }^{2)}$ \\ Jurusan Teknik Sipil, Fakultas Teknik, Universitas Malikussaleh \\ email: ${ }^{l}{ }^{1}$ __wesli@yahoo.co.id, ${ }^{2)}$ jaakidani@gmail.com
}

\begin{abstract}
Abstrak
Komparasi Metode AASHTO 1993 dengan Metode Bina Marga berdasarkan data pada jalan Beureughang-Sido Mulyo. Penelitian ini membandingkan parameter tebal perkerasan, sehingga akan diketahui perbedaan dan persamaan parameter tersebut. Perencanaan tebal perkerasan dengan kedua metode tersebut bertujuan untuk mengetahui sejauh mana perbedaan yang terdapat dari kedua metode tersebut dalam merencanakan tebal perkerasan lentur jalan raya. Dari hasil analisa Metode AASHTO 1993 didapat tebal lapisan pondasi bawah (Sub Base Coarse) dengan jenis bahan sirtu (kelas C) sebesar $17 \mathrm{~cm}$, lapisan pondasi atas (Base Coarse) dengan jenis batu pecah (kelas A) sebesar $10 \mathrm{~cm}$, lapisan permukaan (Surface Coarse) dengan jenis Laston sebesar $5 \mathrm{~cm}$. Sedangkan untuk Metode Bina Marga didapatkan tebal lapisan pondasi bawah (Sub Base Coarse) dengan jenis bahan sirtu (kelas C) sebesar $12 \mathrm{~cm}$, lapisan pondasi atas (Base Coarse) dengan jenis bahan batu pecah (kelas A) sebesar $15 \mathrm{~cm}$, lapisan permukaan (Surface Coarse) dengan jenis bahan Laston sebesar $5 \mathrm{~cm}$.
\end{abstract}

Kata Kunci: Komparasi, Metode AASHTO 1993, Metode Bina Marga

\section{Pendahuluan}

Konstruksi perkerasan jalan berkembang pesat pada zaman keemasan Romawi. Pada saat itu telah mulai dibangun jalan-jalan yang terdiri dari beberapa lapis perkerasan. Perkembangan konstruksi perkerasan jalan seakan terhenti dengan mundurnya kekuasaan Romawi sampai awal abad ke-18. Pada saat itu beberapa ahli Perancis menemukan sistem-sistem konstruksi perkerasan jalan yang sebagian sampai saat ini masih umum digunakan di Indonesia maupun di negara-negara lain di dunia. Semenjak tahun 1920 sampai sekarang teknologi konstruksi perkerasan jalan selalu menggunakan aspal sebagai bahan pengikat, seperti konstruksi perkerasan lentur (flexibel pavement). Perkerasan lentur menggunakan aspal sebagai bahan pengikat, lapisan-lapisan perkerasannya bersifat memikul dan menyebarkan beban lalu lintas ke tanah dasar. Pada perencanaan perkerasan lentur jalan raya sering digunakan Metode AASHTO dan Metode AASHTO ini mempunyai tahapan-tahapan dan pengembanganpengembangan sehingga akan dikhususkan untuk menggunakan Metode AASHTO 1993. Dalam penelitian ini dilakukan komparasi antara Metode AASHTO 1993 dengan Metode Bina Marga. Komparasi dilakukan terhadap parameter perkerasan lentur untuk melihat sejauh mana persamaan dan perbedaan yang terdapat dalam kedua metode tersebut. Dalam penelitian ini akan digunakan data pada jalan Beureughang-Sido Mulyo Kecamatan Kuta Makmur Kabupaten Aceh Utara sebagai bahan studi komparasi. Panjang jalan tersebut adalah 9,256 km yaitu dari Sta $0+000$ sampai Sta $9+200$, lebar perkerasan badan jalan $5 \mathrm{~m}$, dan lebar bahu jalan $0,5 \mathrm{~m}$, serta umur rencana peningkatan jalan Beureughang-Sido Mulyo adalah 10 tahun.

Komparasi Tebal Perkerasan Lentur Metode AASHTO 1993 dengan Metode Bina 


\section{Tinjauan Kepustakaan}

\subsection{Metode AASHTO 1993}

Menurut Siegfried (2007), salah satu metode perencanaan tebal perkerasan adalah metode $A A S H T O$. Metode ini sudah dipakai secara umum di seluruh dunia serta diadopsi sebagai standar perencanaan di berbagai negara. Metode AASHTO 1993 pada dasarnya didasarkan pada metode empiris. Parameter yang dibutuhkan antara lain Structural number (SN), Lalu lintas, Reliability, Faktor drainase dan Serviceability

\subsubsection{Structural number}

Menurut Siegfried (2007), stuctural number merupakan fungsi dari ketebalan lapisan, koefisien relatif lapisan, dan koefisien drainase dinyatakan dalam rumus:

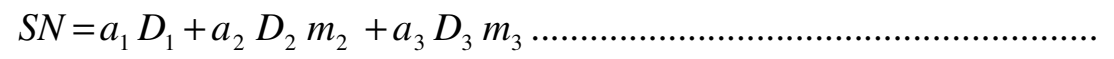

di mana :

$\mathrm{a}_{\mathrm{i}}=$ koefisien relatif lapis ke- $\mathrm{i}$

$\mathrm{D}_{\mathrm{i}} \quad=$ tebal masing-masing lapis perkerasan ke-i $(\mathrm{cm})$

$\mathrm{m}_{\mathrm{i}}=$ koefisien drainase lapis ke-i

$\mathrm{SN}=$ structural number

\subsubsection{Lalu lintas}

Menurut Siegfried (2007), prosedur perencanaan untuk parameter lalu lintas didasarkan pada kumulatif beban gandar standar ekivalen (Equivalent Standard Axle Load, ESAL). Perhitungan untuk ESAL ini didasarkan pada konversi lalu lintas yang lewat terhadap beban gandar standar $8,16 \mathrm{kN}$ dan mempertimbangkan umur rencana, volume lalu lintas, faktor distribusi lajur, serta faktor bangkitan lalu lintas (growth factor).

\subsubsection{Reliabilitas (reliability)}

Menurut Sukirman (1999), reliabilitas adalah nilai probabilitas dari kemungkinan tingkat pelayanan dapat dipertahankan selama masa pelayanan dipandang dari si pemakai jalan. Reliabilitas adalah nilai jaminan bahwa perkiraan beban lalu lintas yang akan memakai jalan tersebut dapat dipenuhi. Reliabilitas dinyatakan dalam tingkat reliabilitas (level of reliability).

\subsubsection{Faktor drainase}

Menurut Sukirman (1999), dalam Metode AASHTO 1993 sistem drainase dari jalan sangat mempengaruhi kinerja jalan tersebut. Tingkat kecepatan pengeringan air yang jatuh atau terdapat pada konstruksi jalan raya bersama-sama dengan beban lalu lintas dan kondisi permukaan jalan sangat mempengaruhi umur pelayanan jalan.

\subsubsection{Indeks permukaan (serviceability)}

Menurut Siegfried (2007), serviceability tingkat pelayanan yang diberikan oleh sistem perkerasan yang dirasakan pengguna jalan. Serviceability parameter utama adalah Present Serviceability Index (PSI). Serviceability merupakan penentu tingkat pelayanan fungsional suatu sistem perkerasan jalan. 


\subsubsection{Persamaan AASHTO 1993}

Menurut Siegfried (2007), dasar perencanaan dari metoda AASHTO baik AASHTO'72, AASHTO'86, maupun metoda terbaru saat sekarang yaitu AASHTO'93 adalah persamaan berikut:

$$
\log W_{18}=Z_{R} x S o+9,36 \log (S N+1)-0,20+\frac{\log \left[\frac{\Delta P S I}{4,2-1,5}\right]}{0,40+\frac{1094}{(S N+1)^{5,19}}}+2,32 \log M r-8,07 \quad \ldots .(2)
$$

di mana:

$\mathrm{W}_{18}=$ kumulatif beban gandar standar selama umur rencana (ESAL).

$\mathrm{Z}_{\mathrm{R}} \quad=$ standar normal deviasi.

So $=$ combined standard error dari prediksi lalu lintas dan kinerja.

$\mathrm{SN}=$ structural number.

$\Delta \mathrm{PSI}=$ selisih antara initial serviceability dengan terminal serviceability.

$\mathrm{Pf} \quad=$ failure serviceability

$\mathrm{Mr} \quad=$ modulus resilien $(\mathrm{psi})$

\subsection{Metode Bina Marga}

\subsubsection{Daya dukung tanah dasar (DDT)}

Daya dukung tanah dasar didapat dari hasil grafik korelasi CBR tanah dasar tehadap DDT, secara analitis nilai DDT dihitung dengan persamaan berikut:

$$
D D T=4,3 \log C B R+1,7
$$

di mana:

DDT = daya dukung tanah dasar.

$\mathrm{CBR}=$ nilai $\mathrm{CBR}$ tanah dasar.

\subsubsection{California Bearing Ratio (CBR)}

Tebal bagian perkerasan ditentukan oleh nilai CBR. CBR merupakan suatu perbandingan antara beban percobaan (test load) dengan beban standar (standard load) dan dinyatakan dalam persentase. Nilai CBR dapat ditentukan dengan mempergunakan cara analitis atau dengan cara grafis.

1. CBR secara analitis

Menurut Alamsyah (2001), agar mempermudah dalam menentukan nilai CBR, maka cara penentuannya dapat dibagi dalam beberapa segmen. Cara analitis dapat mempergunakan rumus sebagai berikut:

$$
C B R_{\text {segmen }}=C B R_{\text {rata-rata }}-\left(\frac{C B R_{\text {maks }}-C B R_{\text {min }}}{R}\right) \ldots \ldots \ldots \ldots \ldots \ldots \ldots \ldots \ldots \ldots \ldots
$$

di mana :

$\mathrm{CBR}_{\text {segmen }}=\mathrm{CBR}$ masing-masing

$\mathrm{CBR}_{\text {rata-rata }}=\mathrm{CBR}$ rata-rata keseluruhan

$\mathrm{CBR}_{\text {maks }}=$ nilai $\mathrm{CBR}$ tertinggi

$\mathrm{CBR}_{\min }=$ nilai $\mathrm{CBR}$ terendah

$\mathrm{R}=$ = nilai tergantung jumlah data 
2. CBR secara grafis

Alamsyah (2001), dalam menentukan nilai CBR dengan cara ini, prosedurnya adalah sebagai berikut: Tentukan nilai CBR yang terendah, Tentukan berapa banyak nilai CBR yang sama atau lebih besar dari masing-masing nilai CBR dan kemudian disusun secara tabelaris mulai dari nilai CBR yang terkecil sampai yang terbesar. Angka terbanyak diberi nilai 100\%, angka yang lain merupakan persentase dari $100 \%$. Dibuat grafik hubungan antara harga CBR dan persentase jumlah. Nilai CBR segmen adalah nilai pada keadaan $90 \%$.

\subsubsection{Umur rencana}

Menurut Alamsyah (2001), umur rencana perkerasan jalan adalah jumlah tahun dari saat jalan tersebut dibuka untuk lalu lintas kendaraan sampai diperlukan perbaikan yang bersifat struktural. Selama umur rencana tersebut pemeliharaan perkerasan jalan tetap harus dilakukan. Umur rencana perkerasan jalan baru diambil 20 tahun dan untuk peningkatan jalan 10 tahun. Umur rencana yang lebih besar dari 20 tahun tidak lagi ekonomis.

\subsubsection{Lalu lintas}

Menurut Sukirman (1999), tebal lapisan perkerasan jalan ditentukan dari beban yang akan dipikul. Jumlah kendaraan yang hendak memakai jalan dinyatakan dalam volume lalu lintas. Volume lalu lintas didefinisikan sebagai jumlah kendaraan yang melewati satu titik pengamatan selama satu tahun waktu. Dengan memperhatikan faktor hari, bulan, musim di mana perhitungan dilakukan, dapat diperoleh data lalu lintas harian rata-rata yang representatif.

\subsubsection{Faktor regional (FR)}

Menurut Anonim 2 (1987), keadaan lapangan mencakup permeabilitas tanah, bentuk alinyemen serta persentase keadaan dengan berat $\geq 13$ ton, dan kendaraan yang berhenti, sedangkan keadaan iklim mencakup curah hujan ratarata pertahun. Menurut Wesli (2008), Dalam nilai $R_{T}$ dan persentase kendaraan berat yang lewat pada suatu lintasan jalan dapat ditentukan besar faktor regional (FR) seperti yang diperlihatkan pada Tabel 1.

Tabel 1 Faktor regional (FR)

\begin{tabular}{|c|c|c|c|c|c|c|}
\hline \multirow{2}{*}{$\begin{array}{l}\text { Curah } \\
\text { Hujan }\end{array}$} & \multirow{2}{*}{\multicolumn{2}{|c|}{$\begin{array}{c}\text { Kelandaian I }(<6 \%) \\
\% \text { Kendaraan Berat }\end{array}$}} & \multicolumn{2}{|c|}{$\begin{array}{c}\text { Kelandaian II (6-10 \% } \\
\% \text { Kendaraan Berat }\end{array}$} & \multicolumn{2}{|c|}{$\frac{\text { Kelandaian III (> } 10 \%}{\text { \% Kendaraan Berat }}$} \\
\hline & $\%$ ne & & $<30 \%$ & $>30 \%$ & $<30 \%$ & $30 \%$ \\
\hline $\begin{array}{c}\text { Iklim I } \\
900 \mathrm{~mm} / \mathrm{thn}\end{array}$ & 0,5 & $1,0-1,5$ & 1,0 & $1,5-2,0$ & 1,5 & $2,0-2,5$ \\
\hline $\begin{array}{c}\text { Iklim II > } \\
900 \mathrm{~mm} / \mathrm{thn}\end{array}$ & 1,5 & $2,0-2,5$ & 2,0 & $2,5-3,0$ & 2,5 & $3,0-3,5$ \\
\hline
\end{tabular}

Sumber : Anonim 2, 1987

\subsubsection{Indeks permukaan}

Menurut Anonim 2 (1987), indeks permukaan ini menyatakan nilai dari pada kerataan atau kehalusan serta kekokohan permukaan yang bertalian dengan tingkat pelayanan bagi lalu lintas yang lewat. Indeks permukaan ini dibedakan atas indeks permukaan awal umur rencana (IPo) dan indeks permukaan pada akhir umur rencana (IPt). 


\subsubsection{Koefisien kekuatan relatif}

Menurut Anonim 2 (1987), koefisien kekuatan relatif (a) masing-masing bahan dan kegunaannya sebagai lapis permukaan, pondasi atas, pondasi bawah, ditentukan secara korelasi sesuai nilai Marshall Test (untuk bahan dengan aspal), kuat tekan (untuk bahan yang distabilisasi dengan semen atau kapur), atau CBR (untuk bahan lapis pondasi bawah).

\subsubsection{Indeks tebal perkerasan}

Menurut Sukirman (1999), komponen perkerasan relatif (a) dari masingmasing lapisan perkerasan jangka panjang, di mana penentuan tebal perkerasan dinyatakan oleh indeks tebal perkerasan (ITP), menggunakan persamaan berikut:

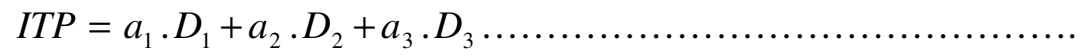

di mana :

ITP $=$ indeks tebal perkerasan

$\mathrm{a}_{\mathrm{i}} \quad=$ koefisien relatif lapis ke-i

$\mathrm{D}_{\mathrm{i}} \quad=$ tebal masing-masing lapis perkerasan ke-i $(\mathrm{cm})$

\section{Metode Penelitian}

Tahap awal yang dilakukan adalah studi kepustakaan terhadap bahan-bahan yang diperlukan dalam penelitian ini. Kemudian untuk tahap berikutnya mengumpulkan data-data yang diperlukan dalam perhitungan yang diperoleh dari Dinas-dinas terkait dan melalui pengamatan langsung di lapangan. Dalam hal ini data yang dikumpulkan adalah data primer dan data sekunder. Data primer terdiri dari data lalu lintas, data CBR tanah dasar, data pertumbuhan lalu lintas, dan data kelandaian jalan. Sedangkan data sekunder terdiri dari data curah hujan, gambar lokasi proyek, dan gambar potongan melintang jalan. Setelah data-data terkumpul dan bahan-bahan telah lengkap, maka dilanjutkan dengan tahap pengolahan data yaitu dengan menggunakan Metode AASHTO 1993 dan Metode Bina Marga. Hal utama yang dilakukan adalah input parameter perencanaan dari masing-masing metode. Parameter perencanaan dari Metode AASHTO 1993 terdiri dari lalu lintas, modulus elastisitas, serviceability, reliabilitas, dan faktor drainase. Sedangkan parameter perencanaan dari Metode Bina Marga terdiri dari lalu lintas, daya dukung tanah dasar, indeks permukaan, dan faktor regional. Dari nilai parameter perencanaan tersebut dapat ditentukan nilai indeks tebal perkerasan atau structural number dan diperoleh tebal perkerasan untuk masing-masing lapisan.

\section{Hasil dan Pembahasan}

\subsection{Hasil}

Nilai daya dukung tanah dasar (DDT) dari nilai CBR segmen diperoleh menggunakan perbandingan antara grafis CBR skala logaritma dan grafis DDT skala linier. Untuk Metode Bina Marga nilai daya dukung tanah sebesar 4,9. Sedangkan Metode AASHTO 1993 sebesar 8160 psi. Secara grafis diperoleh nilai $\mathrm{CBR}_{\text {rencana }}$ sebesar 5,44\% dan secara analitis diperoleh nilai CBR sebesar 7,22\%.

Faktor yang mempengaruhi pertumbuhan lalu lintas adalah perkembangan daerah, bertambahnya kesejahteraan masyarakat, dan lain sebagainya. Faktor pertumbuhan lalu lintas sebesar $5,7 \%$. Volume lalu lintas rata-rata untuk jenis kendaraan ringan 2 ton diperoleh 83 kendaraan/hari, untuk truk 2 as 8 ton 
diperoleh 46 kendaraan/hari, untuk truk 2 as 13 ton diperoleh 5 kendaraan/hari dan untuk jenis kendaraan truk 3 as 20 ton diperoleh 2 kendaraan/hari. Jadi jumlah keseluruhan kendaraan berjumlah 136 kendaraan/hari/2 jurusan. Untuk LHR pada awal umur rencana diperoleh jumlah kendaraan yang berjumlah 143,752 kendaraan LHR pada akhir umur rencana berjumlah 250,243 kendaraan.

Indeks permukaan pada awal umur rencana (IPo) diperoleh 3,9-3,5, Indeks permukaan pada akhir umur rencana (IPt), dengan nilai LER sebesar 22 kendaraan dan klasifikasi jalan jenis lokal IPt sebesar 1,5. Serviceability pada awal umur rencana diperoleh Po sebesar 4,2, indeks permukaan pada akhir umur rencana diperoleh Pt sebesar 2,0 dan untuk Metode AASHTO 1993 terdapat satu nilai lagi yang diberikan dalam indeks permukaan akhir diperoleh Pf sebesar 1,5. Untuk lapisan permukaan material yang digunakan adalah laston (AC-BC), Koefisien relatif $\left(a_{1}\right)$ sebesar 0,40 . Lapisan pondasi atas material batu pecah kelas A koefisien relatif $\left(\mathrm{a}_{2}\right)$ sebesar 0,14 , dan lapisan pondasi bawah material sirtu kelas C koefisien relatif $\left(\mathrm{a}_{3}\right)$ sebesar 0,11. Metode AASHTO 1993 nilai koefisien kekuatan relatif lapisan permukaan sebesar 0,42. Lapisan pondasi atas sebesar 0,14 dan untuk lapisan pondasi bawah sebesar 0,08. Dengan menggunakan grafik penentuan indeks tebal perkerasan, didapat besarnya nilai ITP adalah 5,4. Nilai structural number (SN) ini diperoleh dengan metode coba-coba yang dihitung untuk tiap-tiap lapisan.

Nilai beban gandar standar ekivalen (ESAL) diperoleh berdasarkan jumlah ESAL tiap-tiap jenis kendaraan. Untuk jenis kendaraan truk 2 as diperoleh ESAL sebesar 4839,9 ESALs/thn, jenis kendaraan truk 3 as ESAL sebesar 306,6 ESALs/thn, sehingga untuk ESAL per tahun diperoleh sebesar 5147 ESALs/thn dan ESAL selama umur rencana 10 tahun sebesar 66894 ESALs. Nilai ESAL untuk tiap jenis kendaraan. Faktor distribusi lajur ini diasumsikan mempunyai 1 lajur, maka nilai persen untuk lajur rencana diambil $100 \%$. Tingkat reliabilitas tergantung volume lalu lintas ataupun klasifikasi jalan yang direncanakan. Klasifikasi jalan termasuk ke jalan dalam kota dan berfungsi sebagai jalan lokal, maka tingkat reliabilitas diambil sebesar $80 \%$. Dari nilai tingkat reliabilitas ditentukan nilai $\mathrm{Z}_{\mathrm{R}}$ sebesar $-0,841$.

\subsection{Pembahasan}

CBR merupakan suatu perbandingan antara beban percobaan (test load) dengan beban standar (standard load) dan dinyatakan dalam persentase. CBR digunakan untuk menyatakan kualitas tanah dasar atau mengetahui kemampuan daya dukung tanah dasar dalam memikul beban. Data volume lalu lintas dapat diperoleh dari pos-pos rutin yang ada di sekitar lokasi. Jika tidak terdapat pos-pos rutin di dekat lokasi atau untuk pengecekan data, data volume lalu lintas ini dilakukan secara manual di tempat-tempat yang dianggap perlu. Dengan memperhatikan faktor hari, bulan, musim, dapat diperoleh data lalu lintas harian rata-rata (LHR) yang representatif. Konstruksi perkerasan jalan menerima beban lalu lintas yang dilimpahkan melalui roda-roda kendaraan. Besarnya beban yang dilimpahkan tersebut tergantung dari berat total kendaraan, konfigurasi sumbu, bidang kontak antara roda dan perkerasan, kecepatan kendaraan, dan sebagainya. Oleh karena itu perlu adanya beban standar sehingga semua beban lainnya dapat 
diekivalensikan ke beba standar tersebut. Beban standar merupakan beban sumbu tunggal beroda ganda seberat 18.000 pon $(8,16$ ton), (Sukirman, 1999). Dalam Metode Bina Marga jumlah jalur rencana ini ditentukan berdasarkan persentase kendaraan yang berada pada lajur rencana, yaitu lajur dengan volume kendaraan berat terbesar. Jika ruas jalan tersebut tidak memiliki batas lajur, maka jumlah lajur dapat ditentukan berdasarkan lebar perkerasannya. Koefisien distribusi kendaraan (C) ditentukan berdasarkan jumlah jalur rencana. Koefisien distribusi kendaraan diberikan untuk kendaraan ringan dua arah dan kendaraan berat dua arah. Nilai koefisien distribusi kendaraan ini digunakan untuk dapat menghitung nilai lintas ekivalen permulaan (LEP) dan lintas ekivalen akhir (LEA). Keadaan lapangan mencakup permeabilitas tanah, perlengkapan drainase, bentuk alinyemen, serta persentase kendaraan dengan berat $\geq 13$ ton, dan kendaraan yang berhenti, sedangkan keadaan iklim mencakup curah hujan rata-rata per tahun. Faktor regional (FR) diperhitungkan sebagai faktor koreksi sehubungan dengan kondisi suatu daerah. Dalam penentuan tebal perkerasan faktor regional hanya dipengaruhi oleh bentuk alinyemen (kelandaian dan tikungan), persentase kendaraan berat dan yang berhenti serta iklim (curah hujan), (Anonim 2, 1987).

Kinerja perkerasan dapat dinyatakan dengan indeks permukaan (serviceability). Indeks permukaan diperoleh dari pengamatan kondisi jalan, meliputi kerusakan-kerusakan seperti retak-retak, alur-alur, lubang-lubang, lendutan pada lajur roda, kekasaran permukaan, dan sebagainya yang terjadi selama umur jalan tersebut. Dalam Metode Bina Marga indeks permukaan terdiri dari indeks permukaan pada awal umur rencana (IPo) dan indeks permukaan pada akhir umur rencana (IPt). Sedangkan dalam Metode AASHTO 1993 terdapat satu nilai lagi yang diberikan untuk perkerasan yang sudah rusak dan tidak bisa dilewati atau failure serviceability (Pf). Koefisien kekuatan relatif (a) diperoleh berdasarkan bahan perkerasan atau material yang digunakan pada masing-masing lapisan perkerasan. Koefisien kekuatan relatif masing-masing bahan dan kegunaannya sebagai lapis permukaan, lapis pondasi atas, lapis pondasi bawah, ditentukan secara korelasi sesuai nilai Marshall Test (untuk bahan dengan aspal), kuat tekan (untuk bahan yang distabilisasi dengan semen atau kapur), atau CBR untuk bahan lapis pondasi bawah, (Anonim, 1989). Dalam Metode Bina Marga indeks tebal perkerasan (ITP) merupakan fungsi dari daya dukung tanah, jumlah lintas ekivalen rencana, faktor regional, serta indeks permukaan pada awal umur rencana dan indeks permukaan pada akhir umur rencana. Dalam Metode AASHTO 1993 nilai structural number (SN) merupakan fungsi dari ketebalan lapisan, koefisien relatif lapisan (layer coefficients), dan koefisien drainase (drainage coefficients).

Dalam Metode AASHTO 1993 prosedur perencanaan untuk parameter lalu lintas didasarkan pada beban gandar standar ekivalen (ESAL). Perhitungan untuk ESAL ini didasarkan pada konversi lalu lintas yang lewat terhadap beban gandar standar $8,16 \mathrm{kN}$ dan mempertimbangkan umur rencana, volume lalu lintas, faktor distribusi lajur, serta faktor pertumbuhan lalu lintas (Siegfried, 2007). Dalam AASHTO 1993 untuk menghitung nilai ESAL terdapat nilai faktor distribusi lajur. Jumlah beban ekivalen yang dihitung menunjukkan jumlah beban untuk semua lajur dan kedua arah. Untuk perancangan, jumlah beban ini harus didistribusikan 
menurut arah dan lajur rencana. Faktor distribusi lajur ini ditentukan untuk menghitung nilai ESAL. Dalam Metode AASHTO 1993 konsep reliabilitas untuk perencanaan perkerasan didasarkan pada beberapa ketidaktentuan (uncertainties) dalam proses perencanaan untuk meyakinkan alternatif-alternatif berbagai perencanaan. Tingkatan reliabilitas ini yang digunakan tergantung pada volume lalu lintas, klasifikasi jalan yang akan direncanakan, maupun ekspektasi dari pengguna jalan.

Tabel 2 Parameter desain tebal perkerasan

\begin{tabular}{|c|c|c|c|}
\hline No & Perhitungan & AASHTO 1993 & Bina Marga \\
\hline 1. & CBR & $5,44 \%$ & $5,44 \%$ \\
\hline 2. & DDT & - & 4,9 \\
\hline 3. & Modulus resilien tanah dasar & $8160 \mathrm{psi}$ & - \\
\hline \multirow[t]{9}{*}{4.} & Lalu Lintas: & & \\
\hline & - LHRp & - & 143,752 kend. \\
\hline & - LHRa & - & 250,243 kend. \\
\hline & - LEP & - & 15,6 kend. \\
\hline & - LEA & - & 27,158 kend. \\
\hline & - LET & - & 22 kend. \\
\hline & - LER & - & 22 kend. \\
\hline & ESAL per tahun & 5147 ESALs & - \\
\hline & ESAL 10tahun & 66.894 ESALs & - \\
\hline \multirow[t]{3}{*}{5.} & Pertumbuhan lalu lintas & & \\
\hline & - Awal umur rencana & $5,7 \%$ & $5,7 \%$ \\
\hline & - Akhir umur rencana & $5,7 \%$ & $5,7 \%$ \\
\hline 6. & Reliabilitas & $80 \%$ & - \\
\hline 7. & Combined Standard Error (So) & 0,40 & - \\
\hline 8. & Standar deviasi $\left(\mathrm{Z}_{\mathrm{R}}\right)$ & $-0,841$ & - \\
\hline \multirow[t]{4}{*}{9.} & Serviceability: & & \\
\hline & - Indeks permukaan awal (Po) & 4,2 & $3,9-3,5$ \\
\hline & - Indeks permukaan akhir $(\mathrm{Pt})$ & 2,0 & 1,5 \\
\hline & - Failure Serviceability (Pf) & 1,5 & - \\
\hline 10. & Faktor drainase & 1,00 & - \\
\hline 11. & Faktor regional & - & 2,5 \\
\hline 12. & $\begin{array}{l}\text { Indeks tebal perkerasan (ITP) } \\
\text { atau Structural Number (SN) }\end{array}$ & 4,8 & 5,4 \\
\hline \multirow[t]{4}{*}{13.} & Bahan Perkerasan & & \\
\hline & - Lapisan Permukaan & Laston & Laston \\
\hline & - Lapisan Pondasi Atas & Batu pecah kelas A & Batu pecah kelas A \\
\hline & - Lapisan Pondasi Bawah & Sirtu kelas C & Sirtu kelas C \\
\hline \multirow[t]{3}{*}{14.} & Koefisien kekuatan relatif & & \\
\hline & $-\mathrm{a} 1$ & 0,42 & 0,40 \\
\hline & $-\mathrm{a} 2$ & 0,14 & 0,14 \\
\hline \multirow[t]{5}{*}{15.} & $-\mathrm{a} 3$ & 0,08 & 0,11 \\
\hline & Tebal masing-masing lapisan & & \\
\hline & - Lapisan Permukaan & $5 \mathrm{~cm}$ & $5 \mathrm{~cm}$ \\
\hline & - Lapisan Pondasi Atas & $10 \mathrm{~cm}$ & $15 \mathrm{~cm}$ \\
\hline & - Lapisan Pondasi Bawah & $17 \mathrm{~cm}$ & $12 \mathrm{~cm}$ \\
\hline
\end{tabular}


Perbandingan parameter desain perkerasan lentur jalan raya dari kedua metode tersebut diperlihatkan pada Tabel 2 perbedaan parameter desain yang digunakan dan hasil yang berbeda juga dalam merencanakan tebal perkerasan dengan Metode AASHTO 1993 dan Metode Bina Marga. Untuk nilai CBR diperoleh nilai yang sama yaitu sebesar 5,44 \% karena dalam Metode AASHTO 1993 dan Metode Bina Marga sama-sama menghitung CBR rencana dengan cara yang sama, di mana nilai CBR ini digunakan untuk menghitung nilai daya dukung tanah.

Dalam menentukan indeks tebal perkerasan atau structural number untuk Metode AASHTO 1993 digunakan parameter modulus elastisitas tanah yang diperoleh sebesar 8160 psi sedangkan dengan Metode Bina Marga diperoleh nilai daya dukung tanah (DDT) sebesar 4,9.

\section{$5 \quad$ Kesimpulan dan Saran}

\subsection{Kesimpulan} berikut:

Dari uraian diatas, maka dapat disajikan beberapa kesimpulan sebagai

1. Tidak terdapat perbedaan nilai terhadap nilai CBR antara kedua metode. Sedangkan untuk nilai tanah dasar digunakan parameter desain yang berbeda antara kedua metode. Untuk Metode AASHTO 1993 menggunakan modulus resilien tanah yang diperoleh sebesar 8160 psi dan untuk Metode Bina Marga menggunakan nilai daya dukung tanah (DDT) yang diperoleh sebesar 4,9,

2. Untuk parameter desain lalu lintas, Metode AASHTO 1993 didasarkan pada ESAL sebesar 66.894 ESALs. Metode Bina Marga parameter lalu lintas didasarkan pada lintas ekivalen rencana sebanyak 22 kendaraan. Jumlah kendaraan Metode AASHTO 1993 lebih besar dari Metode Bina Marga, karena dalam Metode AASHTO 1993 perhitungan untuk ESAL ini dikonversikan terhadap beban gandar standar $8,16 \mathrm{kN}$ dan mempertimbangkan umur rencana, volume lalu lintas, faktor distribusi lajur, serta faktor pertumbuhan lalu lintas. Pada metode Bina Marga dikonversikan ke lintas ekivalen.

3. Untuk parameter desain indeks tebal perkerasan dalam Metode AASHTO 1993 nilai structural number (SN) sebesar 4,8, dalam Metode Bina Marga indeks tebal perkerasan (ITP) sebesar 5,4. Nilai SN Metode AASHTO 1993 lebih kecil dari Metode Bina Marga karena lebar perkerasan yang direncanakan tidak terlalu besar, sehingga besar nilai SN tersebut sudah memenuhi untuk merencanakan tebal perkerasan.

4. Tebal lapisan perkerasan Metode Bina Marga lapisan permukaan material laston (AC-BC) sebesar $5 \mathrm{~cm}$. Lapisan pondasi atas material batu pecah (kelas A) $15 \mathrm{~cm}$, dan lapisan pondasi bawah material sirtu (kelas C) $12 \mathrm{~cm}$. Tebal lapisan perkerasan Metode AASHTO 1993 lapisan permukaan sebesar $5 \mathrm{~cm}$, lapisan pondasi atas sebesar $10 \mathrm{~cm}$, dan lapisan pondasi bawah sebesar $17 \mathrm{~cm}$.

5. Tebal lapisan pondasi atas dan lapisan pondasi bawah yang dihasilkan dengan Metode AASHTO 1993 lebih ekonomis dibandingkan dengan tebal lapisan pondasi atas dan lapisan pondasi bawah dengan Metode Bina Marga. Sehingga tebal perkerasan dengan menggunakan Metode AASHTO 1993 ini lebih efisien dari segi penggunaan material. 


\subsection{Saran}

Berdasarkan hasil penelitian dapat diberikan beberapa saran sebagai bahan pertimbangan untuk sebagai berikut:

1. Perlu dilanjutkannya penelitian mengenai perencanaan perkerasan lentur jalan raya dengan Metode AASHTO 1993 untuk kesesuaiannya di Indonesia.

2. Diperlukannya penelitian lebih lanjut terhadap parameter desain modulus resilient tanah dasar pada Metode AASHTO 1993 dalam fungsinya sebagai salah satu parameter desain dalam merencanakan tebal perkerasan khususnya untuk melihat kondisi tanah dasar.

3. Perencanaan tebal perkerasan dengan menggunakan Metode AASHTO 1993 menghabiskan waktu lebih singkat dalam menyelesaikannya, akan tetapi metode ini sulit dipahami. Sedangkan dengan menggunakan Metode Bina Marga menghabiskan waktu lebih lama dalam menyelesaikannya, akan tetapi metode ini lebih mudah dipahami.

\section{Daftar Kepustakaan}

Alamsyah, A.A, 2001, Rekayasa Jalan Raya, UMM Press, Malang.

Anonim 1, 1986, AASHTO Guide for Design of Pavement Structures, 444 N. Capitol Street, N. W., Suite 225, Washington, D. C. 20001.

Anonim 2, 1987, Tata Cara Perencanaan Tebal Perkerasan Lentur Jalan Raya Dengan Metode Analisa Komponen, Dewan Standardisasi Nasional, Jakarta.

Anonim 3, 1993, AASHTO Flexible Pavement Structural Design, Http://pavementinteractive.org./index.php?title=1993_AASHTO_Flexible

_Pavement_Structural_Design, diunduh tanggal 15 Januari 2010.

Anonim 4, 2006, Laporan Perencanaan Teknik Peningkatan Jalan Beureughang-Sido Mulyo, Dinas Pekerjaan Umum, Kabupaten Aceh Utara.

Siegfried dan Sri Atmaja P. Rosyidi, 2007, Deskripsi Perencanaan Tebal Perkerasan Jalan Menggunakan Metode AASHTO 1993, Http:// labtransportumy.files.wordpress.com/2007/11/web-publish-narasiAASHTO 1993.pdf, diunduh tanggal 20 Desember 2008.

Sukirman, 1999, Perkerasan Lentur Jalan Raya, Nova, Bandung.

Wignall, et al, 1999, Proyek Jalan Teori dan Praktek Jilid Ke-4, Erlangga, Jakarta.

Wesli, 2008, Drainase Perkotaan, Graha Ilmu, Yogyakarta 


\section{UCAPAN SELAMAT}

KELUARGA BESAR JURUSAN TEKNIK SIPIL UNIVERSITAS MALIKUSSALEH

MENGUCAPKAN SELAMAT ATAS PELANTIKAN

\section{PROF. DR. H. APRIDAR, SE., M.SI}

\section{SEBAGAI REKTOR UNIVERSITAS MALIKUSSALEH PERIODE 2014 -2018}

KETUA JURUSAN

FASDARSYAH, ST., MT

KEPALA LABORATORIUM STRUKTUR

YULIUS RIEF ALKHALY, ST., MT
SEKRETARIS JURUSAN

FADHLIANI, ST., M.ENG

KEPALA LABORATORIUM

TRANSPOTASI

HAMZANI, ST., MT

PEMIMPIN REDAKSI

TERAS JURNAL

DR. IR. WESLI, MT 